\title{
Dependence of Microcrack Behavior in Wood on Moisture Content during Drying
}

\author{
Hiroyuki Yamamoto, ${ }^{1}$ Hiroki Sakagami, ${ }^{2}$ Yoshio Kijidani, ${ }^{3}$ and Junji Matsumura ${ }^{2}$ \\ ${ }^{1}$ Department of Forest and Forest Products Sciences, Graduate School of Bioresource and Bioenvironmental Sciences, \\ Kyushu University, 6-10-1 Hakozaki, Higashi-ku, Fukuoka 812-8581, Japan \\ ${ }^{2}$ Division of Sustainable Bioresources Science, Faculty of Agriculture, Kyushu University, 6-10-1 Hakozaki, Higashi-ku, \\ Fukuoka 812-8581, Japan \\ ${ }^{3}$ Division of Forest Science, Faculty of Agriculture, Miyazaki University, Miyazaki 889-2192, Japan
}

Correspondence should be addressed to Hiroki Sakagami; h-sakagami@agr.kyushu-u.ac.jp

Received 15 May 2013; Revised 10 July 2013; Accepted 7 August 2013

Academic Editor: Jeffrey Glass

Copyright (C) 2013 Hiroyuki Yamamoto et al. This is an open access article distributed under the Creative Commons Attribution License, which permits unrestricted use, distribution, and reproduction in any medium, provided the original work is properly cited.

A modified confocal laser scanning microscopy (CLSM) system was developed not only to observe the microcracks on the surface of Cryptomeria japonica D. Don in situ at the cellular level but also to obtain information about the moisture content (MC) of the wood surface by measuring the change in its electrical resistivity. The sequential images and changes in the electrical resistivity of the wood surface indicated that microcracks formed between the tracheid and ray parenchyma in the latewood region at $>1.0 E+$ $07 \Omega /$ sq (square). Microcracks formed when the MC of the wood surface was below the fiber saturation point determined through regression analysis of the surface electrical resistivity and MC. Most of the microcracks develop when the surface electrical resistivity ranged from $3.95 E+10$ to $3.60 E+12 \Omega / s q$. When the surface $\mathrm{MC}$ was $\sim 2.5 \%$, microcracks closed and the surface electrical resistivity was either $\sim 1.00 E+15 \Omega /$ sq or outside the measurement range. The modified CLSM and the method to measure the MC of the wood surface can be used to acquire information about the surface MC in specific areas shown in CLSM images. The findings indicated that the MC of the surface of the wood plays an important role in suppressing the emergence of microcracks in drying wood. The modified CLSM system and the method of measuring the MC of the surface of wood can be used to efficiently evaluate methods of drying wood and the quality of dried wood.

\section{Introduction}

Woods are heterogeneous, anisotropic biomaterials composed of various types of tissues. Among the tissues, wood fibers occupy almost the entire volume of wood. Cell walls in wood fiber swell and shrink under the fiber saturation point (FSP). Once environmental conditions such as temperature and relative humidity $(\mathrm{RH})$ have been changed, molecules of water vapor are either absorbed into or desorbed from the cell wall under the FSP so that complicated transformations can occur.

Wood drying is indispensable for minimizing the changes in the dimensions of wood used in practical applications. However, higher drying stress is produced during drying because of the moisture content (MC) gradient between the surface and the core of the wood if an appropriate method of drying is not used. This stress enables checks to form at the weak points in the wood structure, disfiguring the wood and decreasing its physical properties thereby decreasing the range of applications for which the wood can be used. Therefore, it is important to conduct research on minimizing cracking in wood so that the wood can be used in a wider range of advanced applications.

Morén [1] and Hanhijärvi et al. [2] have previously reported that small cracks or "microcracks," which cannot be observed with the naked eye, develop on the wood surface during the early stages of timber drying. Hukka and Tarvainen [3] reported that the number of visible cracks was reduced when an effective drying method was used during the warm-up phase of drying. Avramidis and Mackay [4] also 
reported that visible surface and end cracks disappeared after postdrying conditioning of hem-fir baby squares. However, there has been scant information about microcracking propagation to date.

Perré [5] used an optical microscope equipped with a digital camera to observe the propagation of cracks in both softwood and hardwood under controlled drying conditions. To precisely observe the formation and propagation of microcracks, Sakagami et al. [6] devised a confocal laser scanning microscopy (CLSM) system consisting of a CLSM in an environmental chamber and used the system to observe the in situ propagation of microcracks while drying softwood [7] and ring- and diffuse-porous hardwood [8]. Such a system can be used to observe the formation and propagation of microcracks in any wood under any temperature, $\mathrm{RH}$, and barometric pressure conditions. Sakagami et al. [7] also obtained important information about the relation between microcrack configurations and the MC in the drying wood. Although wood commonly checks around the FSP, microcracks formed above FSP in all wood specimens used for the experiment, so they could not measure MC of the wood surface when microcracks emerged. If the MC of the wood surface when cracks occur is known, it would be possible to derive the time for regulating drying conditions in order to control the moisture condition in wood and prevent large cracks from emerging or decrease the number of cracks in wood because moisture content of surface and interior can be estimated. Therefore, measuring the MC of wood surfaces when microcracks emerge is essential in elucidating the mechanism by which the microcracks form in the wood.

In this study, we measured the MC on the surfaces of samples of drying Cryptomeria japonica to determine how the $\mathrm{MC}$ of the wood changes during drying. The propagation of microcracks and the changes in the MC of both the surface and interior of specimens of Cryptomeria japonica over time were measured using the modified CLSM system, and the relations among them were established.

\section{Materials and Methods}

2.1. Materials and Preparation. A green wood of Cryptomeria japonica D. Don was used in this study. This species is one of the most important plantation trees in Japan and is used for many wood products. Wood specimens were sampled from a tree grown in a private forest in Fukuoka, which is located on the northern part of Kyushu Island. A fresh log was derived from the sapwood of the tree and was cut into longitudinal sticks $(15 \times 15 \mathrm{~mm})$. Two successive longitudinal specimens were then obtained from the sticks to produce two end-matched specimens, which comprised a set of samples, and eight sets of samples were prepared in total. CLSM was used to observe the microcracks in one specimen in each set of samples. Another specimen in each set of samples was weighed to obtain the MC. The final radial, tangential, and longitudinal dimensions of each specimen were 15,15 , and $7 \mathrm{~mm}$, respectively.

All faces of the two end-matched specimens were smoothed using a sliding microtome. More attention was

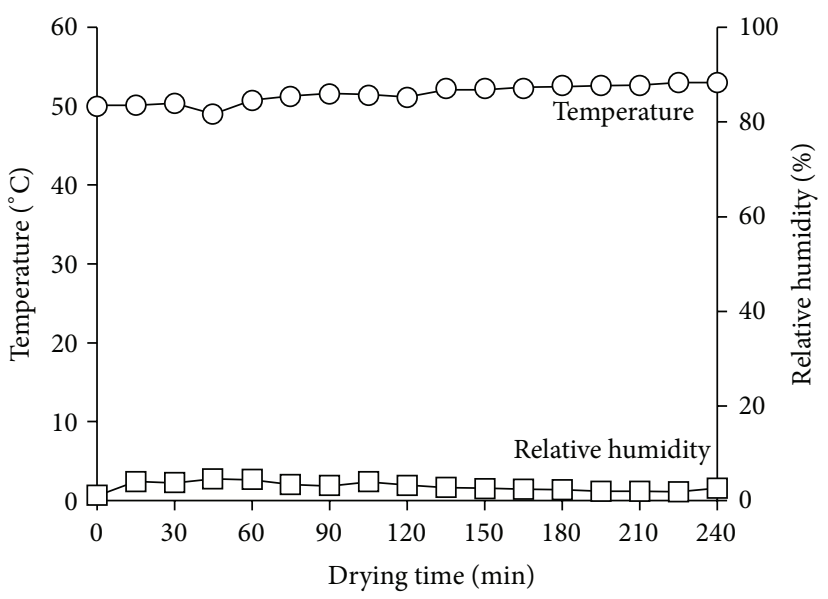

FIGURE 1: Representative example of change in temperature and relative humidity during wood drying.

paid when slicing the surface for transverse observation. The average specific gravity measured for all the air-dry samples after observation by CLSM was $0.49(\mathrm{SD}=0.032)$. The average tangential and radial shrinkages calculated from measuring each side of specimens in green and oven-dried conditions were $7.65(\mathrm{SD}=0.36)$ and $3.80 \%(\mathrm{SD}=0.54)$, respectively.

2.2. Observation Method. The CLSM (BIO-RAD Radiance 2000) system which was devised by Sakagami et al. [6] to observe microcracks in wood in a controlled-environment chamber was modified to measure the electrical resistivity in situ. A probe used to measure electrical resistivity was placed in the system. The temperature and $\mathrm{RH}$ used as the drying conditions in the chamber were $\sim 50^{\circ} \mathrm{C}$ and $<5 \%$. A representative example of the conditions in the chamber is shown in Figure 1.

A set of sapwood specimens was placed on the stage of the CLSM. A dry lens $(4 \times /$ n.a. 0.2 or $10 \times /$ n.a. 0.45$)$ was selected as necessary to observe the propagation of microcracks in the wood specimens. The images were recorded using a $488 \mathrm{~nm}$ excitation wavelength argon-ion laser and a $500 \mathrm{~nm}$ longpass (HQ500LP) emission filter. The scan speed was 166 lines per second. Images of the observed samples were captured every minute until the equilibrium MC of the samples was reached. The electrical resistivity and the weight of the sample were measured in five- and fifteen-minute intervals using an electrical resistivity meter (Hiresta-UP MCP-HT450 Mitsubishi Chemical Analytech Co., Ltd.) and a balance scale that were placed inside the CLSM system. The equilibrium $\mathrm{MC}$ in all specimens was $<3 \%$ during the last stage of drying and was calculated from the weight of the oven-dried specimens.

2.3. Measurement of Surface Moisture Content. The electrical conductivity of wood is associated with the MC of the wood below the FSP. The linear relation of electrical conductivity and MC of eight species of softwoods and a species of hardwood was reported by Stamm [9]. No perceptible deviation between the results for green redwood and for resoaked 
TABLE 1: Applied voltage of electrical resistivity meter.

\begin{tabular}{lc}
\hline Voltage $(\mathrm{V})$ & Electrical resistivity $(\Omega / \mathrm{sq})$ \\
\hline 10 & $<9.99 E+07$ \\
100 & {$[1.00 E+08,9.99 E+08]$} \\
250 & {$[1.00 E+09,9.99 E+09]$} \\
500 & {$[1.00 E+10,9.99 E+10]$} \\
1000 & $>1.00 E+11$ \\
\hline
\end{tabular}

redwood was also observed. The first moisture content measurement by electrical conductivity was devised by Stamm [10]. We used this association to elucidate the surface MC of the wood specimens precisely when microcracks emerged. A resistivity meter equipped with a probe consisting of double metal rings was used to measure the electrical resistivity of the surface of the wood specimens in order to derive the electrical conductivity of the wood. The diameter of the inside ring of the probe was $3 \mathrm{~mm}$, and that of the outside one was $6 \mathrm{~mm}$. The resistivity meter measures the resistivity of the direct current flowing between the two rings. The probe was attached to the transverse surface of the specimen to measure the electrical resistivity of the surface and thus the MC of the specimen. The electrical resistivity was measured in 5-minute intervals for 30 seconds. The voltage applied to the specimens was selected depending on the measured electrical resistivity of the specimens. Applied voltages to measure the electrical resistivity are shown in Table 1.

The desiccator method (Japanese Industrial Standard A 1475) was used to obtain the relation between the electrical resistivity of the surface and the MC of the samples. A total of 180 identically dimensioned specimens were cut from the sapwood of the same fresh Cryptomeria japonica and were oven-dried. The oven-dried specimens were subsequently weighed and were placed in individual desiccators at $50^{\circ} \mathrm{C}$ filled with saturated solutions. The relationships between saturated solutions and relative humidity inside of desiccators at $50^{\circ} \mathrm{C}$ are shown in Table 2 . The weights of the soaking specimens increased for about two weeks, stabilized, and then remained constant at which point we assumed that the specimens had reached their respective equilibrium MC and that there were no MC gradients in the specimens. The electrical resistivity of the surface of the specimens and the weight of the specimens were measured after two weeks. Two regression lines bordering $8 \%$ MC showed the relation between the electrical resistivity and the MC obtained using the measurements.

The logarithm of electrical conductivity is proportional to $\mathrm{MC}$ at low MC ascribed to monolayer absorption. However, the logarithm of electrical conductivity is proportional to the logarithm of MC at high MC ascribed to multilayer absorption under the FSP. We defined the boundary of the regression lines as $8 \% \mathrm{MC}$ because Kuroda and Tsutsumi [11] showed that wood exhibits various electrical conductivities at 8\% MC. Sixty-three (63) specimens showed stable electrical conductivity when the MC of the wood was $<8 \%$, and 97 specimens showed stable electrical conductivity when the $\mathrm{MC}$ of the wood was $>8 \%$. The MC of the wood surface was

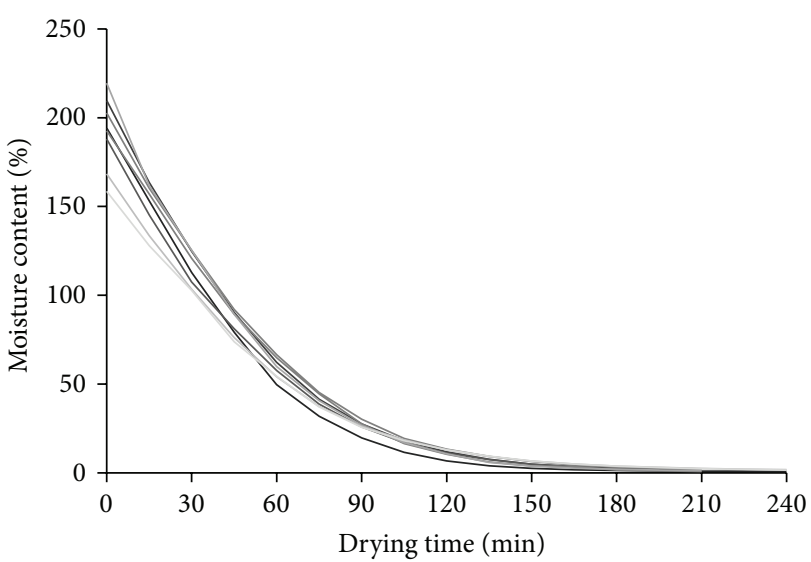

FIGURE 2: Change in moisture content of eight drying specimens. Moisture content was measured every five minutes and was calculated from weight of oven-dried specimens.

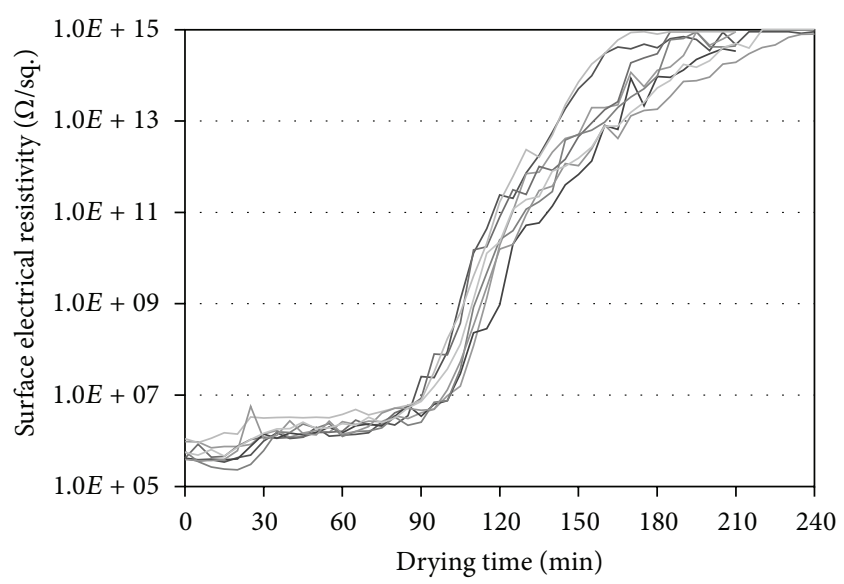

FIgURE 3: Transition of surface electrical resistivity measured on transverse surfaces of eight drying specimens.

then calculated from the two regression lines obtained for the respective $\mathrm{MC}$ ranges.

\section{Results and Discussion}

3.1. Moisture Content of Drying Specimens. The time history of the moisture content (MC) of eight specimens calculated based on the oven-dried weights is shown in Figure 2. The initial MC of the specimens ranged from 158.6 to $219.5 \%$, and the average initial MC was $191.7 \%$. The specimens were then dried, and their MC drastically decreased. The MC of the specimens reached the FSP after 90 minutes. We assumed that microcracks formed in the specimens during this time. The specimens were then dried to their equilibrium MC under the same drying condition. The MC of all the samples at the final stage of drying was $<3 \%$. Microcracks formed on the transverse surfaces of all the specimens under this condition.

3.2. Transition of Surface Electrical Resistivity. Figure 3 shows the transition of the electrical resistivity measured on 
TABLE 2: Relative humidity in desiccators at $50^{\circ} \mathrm{C}$ filled with saturated solutions.

\begin{tabular}{lcccccccccc}
\hline Saturated solution & Glycerin 5\% & Glycerin 20\% & Glycerin 80\% & Glycerin 100\% & $\mathrm{H}_{2} \mathrm{O}$ & $\mathrm{NaCl}$ & $\mathrm{KCl}$ & $\mathrm{KNO}_{3}$ & $\mathrm{MgCl}_{2}$ & $\mathrm{Mg}^{2}\left(\mathrm{NO}_{3}\right)_{2}$ \\
\hline $\mathrm{RH}(\%)$ & $>90$ & $>90$ & 54 & 21 & $>90$ & $>90$ & $>90$ & $>90$ & 42 & 47 \\
\hline
\end{tabular}

the transverse surfaces of the drying samples. The samples were the same ones used to measure the change in the MC, as shown in Figure 2. The electrical resistivity of the surfaces of the samples ranged from $1.68 E+05$ to $5.52 E+05 \Omega /$ sq at the beginning of drying and remained low for 90 minutes of drying. Although water had desorbed from the specimens during this time, the wood fibers in the specimens seemed to remain saturated with free water. Therefore, the electrical resistivity of the surfaces of the specimens remained constant. From 90 minutes, however, the electrical resistivity of the surfaces of the specimens dramatically increased and was close to $1.00 E+15 \Omega / \mathrm{sq}$ at the end of drying. The electrical resistivity of the surfaces of some specimens was outside the measuring range $(\geqq 1.00 E+15 \Omega / \mathrm{sq})$. We assume that the discontinuous characteristics of the electrical resistivity, shown as an inflection point around $90 \mathrm{~min}$, indicate that something occurred on the surface of specimens.

3.3. Relation between Electrical Resistivity and Moisture Content. Figure 4(a) shows the relation between the MC and the logarithm of electrical conductivity (the inverse of the electrical resistivity) measured for the samples whose MC was $<8 \%$. A significant correlation was obtained between the logarithm of electrical conductivity and MC of the samples $(r=0.914, P<0.001)$. Coefficient of determination was very high $\left(r^{2}=0.836\right)$. Therefore, the logarithm of conductivity is proportional to $\mathrm{MC}$ from the scatter diagram. Just as when the $\mathrm{MC}$ of the samples was $<8 \%$, a significant correlation existed between the logarithm of the MC and the logarithm of the conductivity $(r=0.922, P<0.001)$ when the MC of the samples was in the range $8 \%$ to the FSP (Figure 4(b)). From very high coefficient of determination $\left(r^{2}=0.850\right)$, a reliable regression equation was derived. Using the regression equations, information about the $\mathrm{MC}$ of the surface of the samples was obtained.

3.4. Moisture Content and Morphology of Microcracks on the Surface. Figure 5 shows the relation between the in situ propagation of microcracks and the electrical resistivity of the surface of the samples. In addition, the decreasing MC for the samples whose $\mathrm{MC}$ was $<31 \%$, which was the maximum $\mathrm{MC}$ measured using the electrical resistivity meter in the desiccator filled with $\mathrm{H}_{2} \mathrm{O}$, is also shown. The six images show the stages of microcrack propagation: (1) before the microcrack emerges, (2) immediately after the microcrack emerges, (3) the developing microcrack, (4) the largest microcrack, (5) the closing microcrack, and (6) the residual microcrack.

The microcrack did not exist from the early stage of drying until about $90 \mathrm{~min}$ (Figure 5 (1)). The electrical resistivity of the surface of the specimen remained low during this time, as shown in Figure 3. The MC of the surface of the specimen seemed to be above the FSP because the direct current is constant when free water exists in the specimen. Therefore,

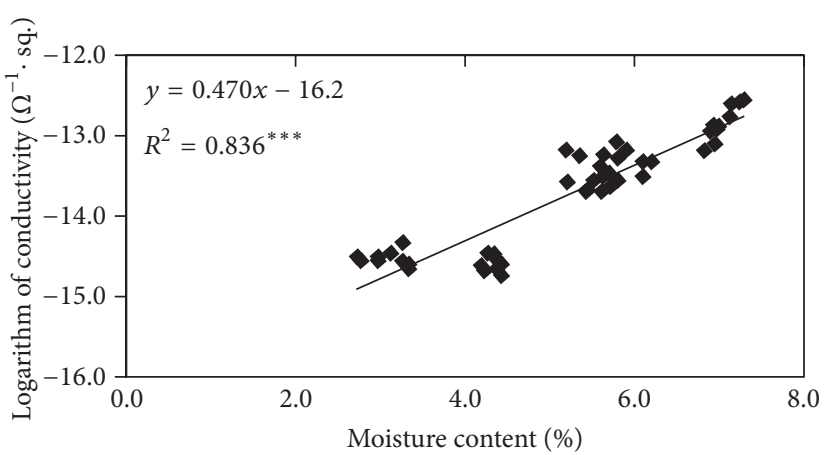

(a)

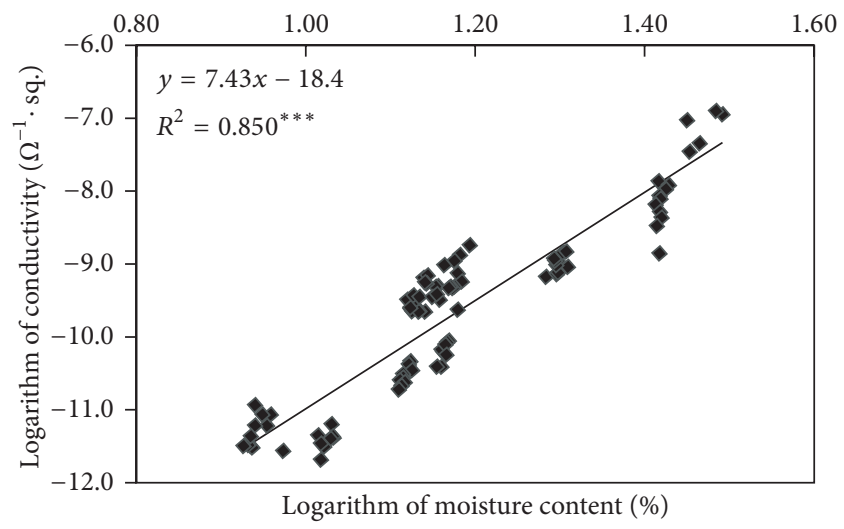

(b)

FIGURE 4: Relation between conductivity and moisture content. (a) Standard curve for logarithm of surface electrical resistivity versus MC below $8 \%$ for 63 specimens. $x$-axis represents moisture content and $y$-axis represents logarithm of surface electrical resistivity. (b) Standard curve for logarithm of surface electrical resistivity versus logarithm of MC above $8 \%$ for 97 specimens. $x$-axis represents logarithm of moisture content and $y$-axis represents logarithm of surface electrical resistivity.

although the MC of the specimen decreased, no microcracks appeared on its surface because the electrical resistivity remained low, resulting in less stress because of no shrinkage. However, a dramatic change happened after the specimens had been drying for 90 minutes: the low electrical resistivity of the specimens suddenly increased. The CLSM image taken for the surface of the specimen at the moment the electrical resistivity suddenly increased is shown in Figure 5 (2). The initial microcrack had appeared between the tracheid and ray parenchyma in the latewood (as indicated by the white arrows). The electrical resistivity and the MC of the surface of the sample at this point were $3.66 E+07 \Omega /$ sq and $28.9 \%$, respectively. The microcrack subsequently spread along the 


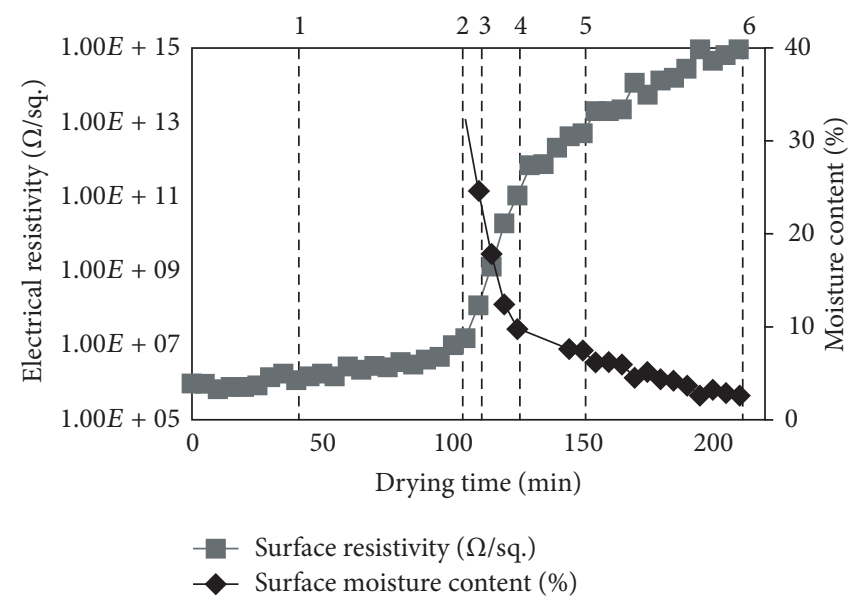

(a)
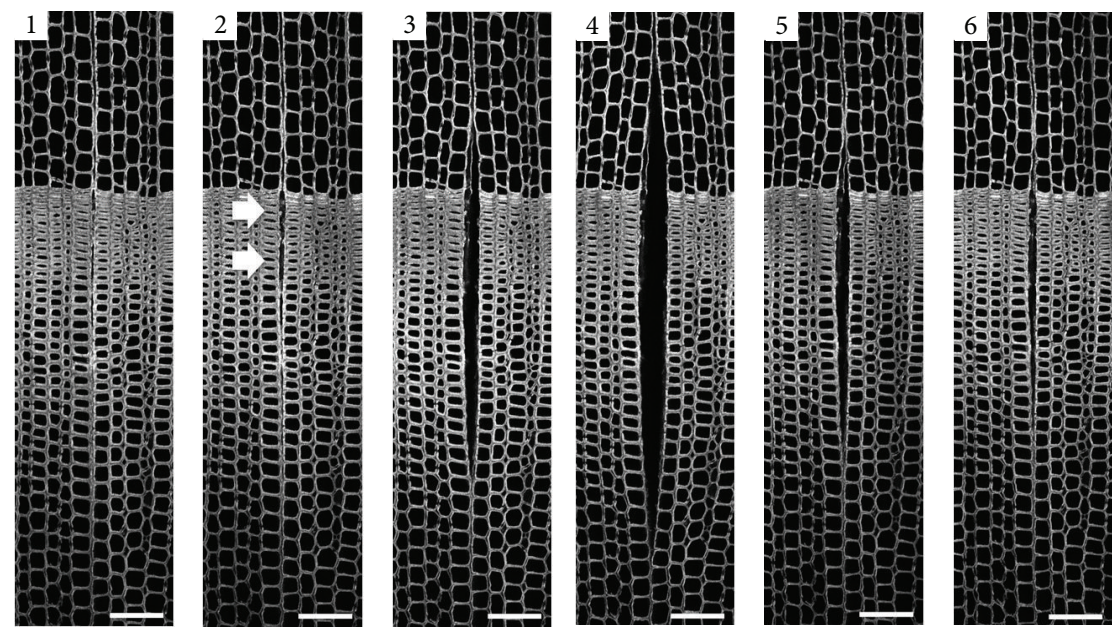

Bar: $100 \mu \mathrm{m}$

(b)

FIGURE 5: Sequential images showing propagation of microcrack in relation to surface electrical resistivity and surface moisture content calculated from regression equations: (1) before microcrack emerges, surface moisture content was above FSP, (2) immediately after microcrack emerges, surface moisture content was around FSP, (3) microcrack develops, (4) largest microcrack, (5) microcrack closes, and (6) residual microcrack.

ray parenchyma and the crack tip advanced in both the bark and pith directions when the electrical resistivity of the surface of the specimen drastically increased. The microcrack then appeared in the latewood region and passed through the growth ring boundary (Figure 5 (3)). The crack tip stopped in the earlywood region before reaching the next growth ring boundary. The microcrack had reached maximum development at this point despite the fact that the electrical resistivity of the surface of the specimen was still increasing (Figure 5 (4)). The electrical resistivity and MC of the surface of the specimen were $1.08 E+11 \Omega /$ sq and $9.9 \%$. Although the electrical resistivity of the surface of the specimen continued to increase at that point, the microcrack started to close. Although the microcrack had almost completely closed at the end of the experiment, it was still visible. The electrical resistivity of the surface of the specimen at the end of drying either approached $1.00 E+15 \Omega$ /sq or was outside the range of measurement. The MC of the surface of the specimen was about $2.5 \%$ (Figure $5(6)$ ).

The behavior of the microcracks in this research was almost identical to that of the microcracks described by Sakagami et al. [7]. The origin of the formation of microcracks is the shrinkage of the surface tissue prior to that of the interior tissue of the wood. The surface layer tissue of the wood was initially below the FSP and started to shrink when the wood was dried. The stress induced by the difference between the rate of shrinkage of the surface and interior tissues then accumulated at a weak point in the tissue. The microcrack seems to emerge when the magnitude of the shrinkage-induced stress is greater than that of the strength of the bonds among the cells in the tissue. This difference between the rate of shrinkage of the surface and interior tissues increased when the microcrack expanded (Figure 5 (2) and (3)) and reached the maximum development (Figure $5(4)$ ). The magnitude 
of the stress contributed by the difference between the rate of shrinkage of the surface and interior tissues may have then decreased (Figure 5 (5) and (6)) when the microcrack closed. The microcrack remained during the final stage of wood drying because the stress at the surface of the wood may have been alleviated or because a small amount of residual stress remained inside the wood. Perré [5] and Sakagami et al. [7], on the other hand, reported that microcracks had completely vanished during the final stage of drying either because of the drying set during the initial stage of drying or because the stress in the wood had been completely alleviated by the end of the experiment.

Although we assumed that the MC of the surface of the specimens was lower than that calculated from the weight of the oven-dried specimen, the actual amount of difference between them was negligible in this research. Nakanishi et al. [12] used a neutron beam to observe water depletion in a disk of fresh Cryptomeria japonica wood and found that the moisture gradient in radial direction of the disk seemed to be high in the annual rings of the wood. Tanaka et al. [13] used X-rays to measure the distribution of moisture in drying Cryptomeria japonica wood and showed that the MC of the latewood tended to be higher than that of the earlywood during drying. Their report showed that it was possible that the latewood retained more moisture than the earlywood. It is possible that the electrical resistivity of the surface of the wood was mainly measured in moister latewood. The electrical resistivity meter measures the resistivity in the area where the current flows freest between the inner and outer rings in the probe, not the average resistivity of the area. Therefore, the amount of difference between the MC of the surface of the wood and that of the specimens was negligible because the electrical resistivity was measured in moister latewood where the current flowed more freely.

We obtained information about the MC of the surface of the wood in the areas shown in the CLSM images. The emergence and propagation of the microcracks in the wood strongly depended on the change in the electrical resistivity of the surface of the wood. This finding indicates that the $\mathrm{MC}$ of the surface of drying wood plays an important role in suppressing the emergence of microcracks. The effect of the MC of the surface of the wood on the behavior of microcracks was elucidated by using the in situ observation system and by measuring the electrical resistivity of the surface of the wood. The in situ observation system and the method of measuring the electrical resistivity of the surface of wood may be used to efficiently evaluate methods of drying wood and the quality of dried wood.

\section{Conclusions}

A modified CLSM system was developed. It consisted of a conventional confocal laser scanning microscope and an electrical resistivity meter placed inside an environmental chamber where the temperature and relative humidity (RH) were precisely controlled. The modified CLSM system enabled us to observe the behavior of microcracks in crosssections of the surface of green Cryptomeria japonica D. Don in situ at the cellular level and to measure the change in the electrical resistivity of the surface of the drying wood. The microcrack emerged when the electrical resistivity of the surface of the wood dramatically increased (around the FSP). The microcrack subsequently developed with increasing electrical resistivity of the surface of the wood, reached the maximum size, and then closed. The modified CLSM system and the method of measuring the MC of the surface of wood can be used to acquire information about the $\mathrm{MC}$ of the surfaces of wood in specific areas shown in CLSM images. The findings indicated that the MC of the surface of the wood plays an important role in suppressing the emergence of microcracks in drying wood. The modified CLSM system and the method of measuring the MC of the surface of wood can be used to efficiently evaluate methods of drying wood and the quality of dried wood.

\section{Acknowledgment}

This research was supported in part by a Grant-in-Aid for Scientific Research (19580192) from the Ministry of Education, Culture, Sports, Science, and Technology of Japan.

\section{References}

[1] T. J. Morén, "Heating and conditioning by steaming during low temperature drying," in Proceedings of the 4th International IUFRO Wood Drying Conference, pp. 341-348, Rotorua, New Zealand, August 1994.

[2] A. Hanhijärvi, P. Wahl, J. Räsänen, and R. Silvennoinen, "Observation of development of microcracks on wood surface caused by drying stresses," Holzforschung, vol. 57, no. 5, pp. 561-565, 2003.

[3] A. Hukka and V. Tarvainen, Höyryn käyttö sahatavaran kuivauksessa, VTT Julkaisuja, 1997.

[4] S. Avramidis and J. F. G. Mackay, "Development of kiln schedules for 4-inch by 4-inch pacific coast hemlock," Forest Products Journal, vol. 38, no. 9, pp. 45-48, 1988.

[5] P. Perré, "The role of wood anatomy in the drying of wood: 'great oaks from little acorns grow,' in Proceedings of the 8th International IUFRO Wood Drying Conference, pp. 11-24, Brasov, Romania, August 2003.

[6] H. Sakagami, J. Matsumura, and K. Oda, "Shrinkage of tracheid cells with desorption visualized by confocal laser scanning microscopy," IAWA Journal, vol. 28, no. 1, pp. 29-37, 2007.

[7] H. Sakagami, K. Tsuda, J. Matsumura, and K. Oda, "Microcracks occurring during drying visualized by confocal laser scanning microscopy," IAWA Journal, vol. 30, no. 2, pp. 179-187, 2009.

[8] H. Sakagami, J. Matsumura, and K. Oda, "In situ visualization of hardwood microcracks occurring during drying," Journal of Wood Science, vol. 55, no. 5, pp. 323-328, 2009.

[9] A. J. Stamm, "The fiber-saturation point of wood as obtained from electrical conductivity measurements," Industrial and Engineering Chemistry, vol. 1, no. 2, pp. 94-97, 1929.

[10] A. J. Stamm, "An electrical conductivity method for determining the moisture content of wood," Industrial and Engineering Chemistry, vol. 2, no. 3, pp. 240-244, 1930.

[11] N. Kuroda and J. Tsutsumi, "Anisotropic behavior of electrical conduction in wood," Mokuzai Gakkaishi, vol. 28, pp. 25-30, 1982 (Japanese). 
[12] T. M. Nakanishi, T. Okano, I. Karakama, T. Ishihara, and M. Matsubayashi, "Three dimensional imaging of moisture in wood disk by neutron beam during drying process," Holzforschung, vol. 52, no. 6, pp. 673-676, 1998.

[13] T. Tanaka, S. Avramidis, and S. Shida, "Evaluation of moisture content distribution in wood by soft X-ray imaging," Journal of Wood Science, vol. 55, no. 1, pp. 69-73, 2009. 

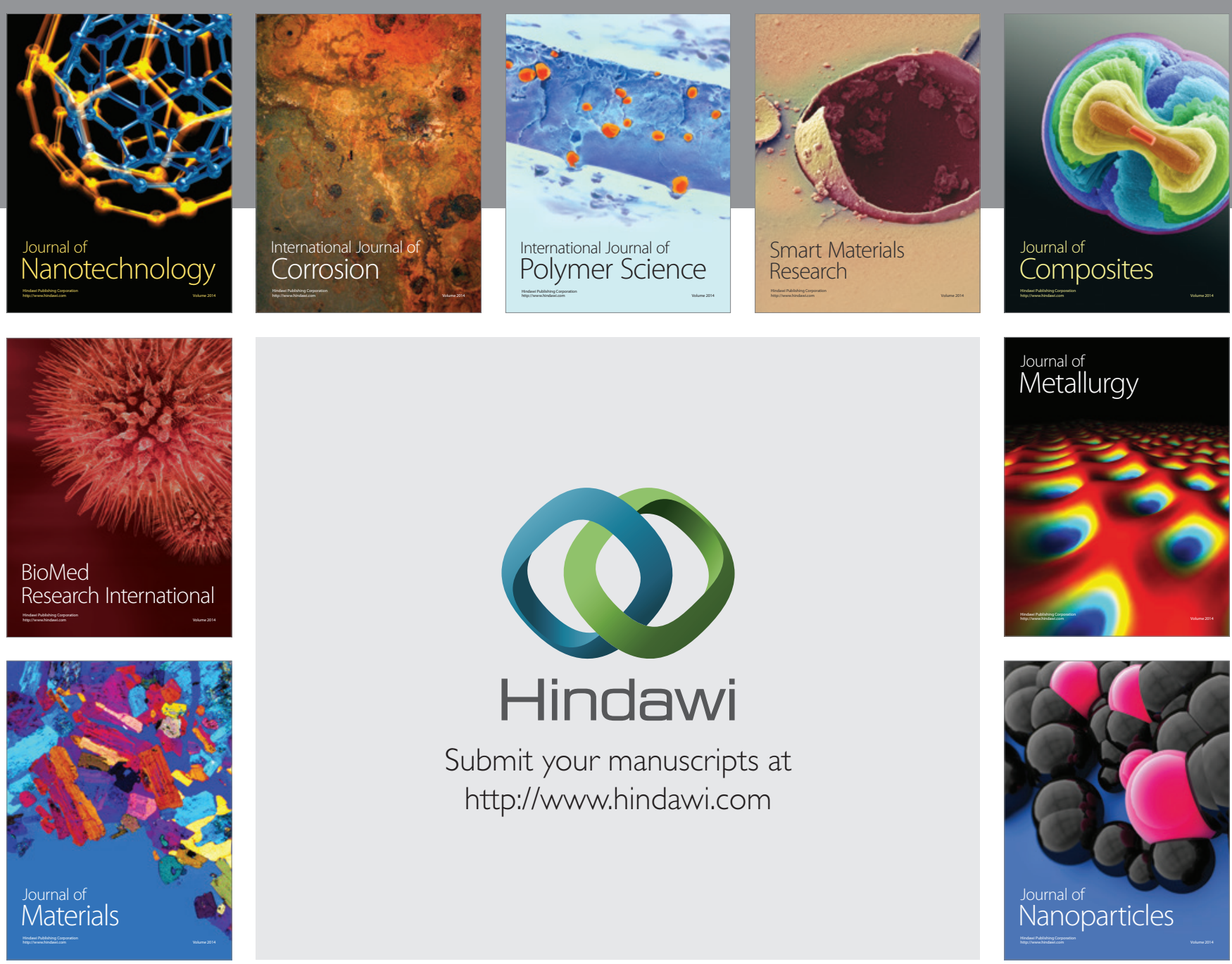

Submit your manuscripts at http://www.hindawi.com
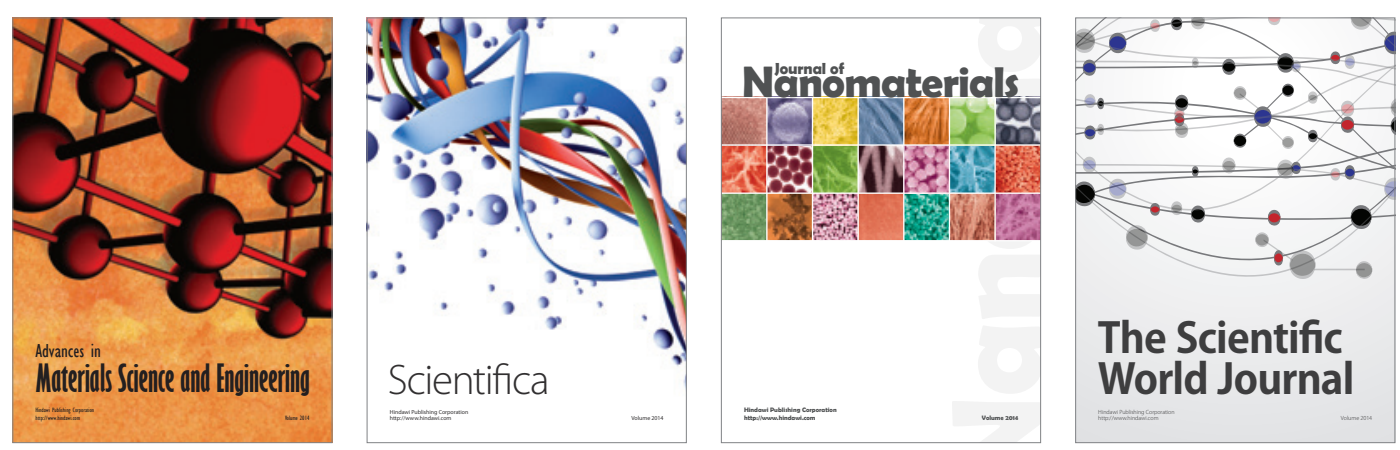

\section{The Scientific World Journal}
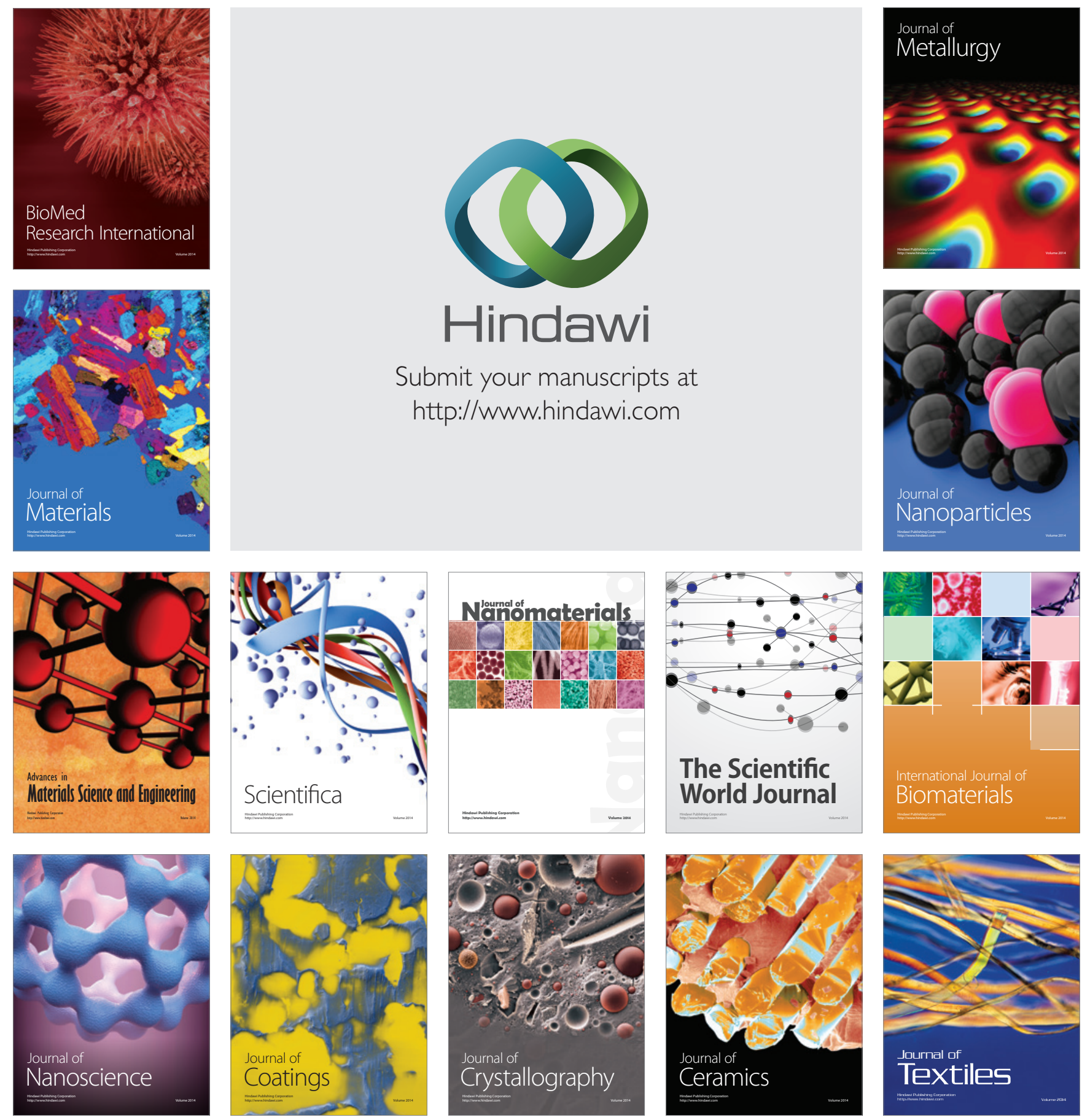